Original

\title{
Self-etching primer systems: changes in dentin bond strength with time
}

\author{
Toru Maeda ${ }^{1)}$, Akira Yamamoto ${ }^{1)}$, Mika Iwasa ${ }^{1)}$, Chikako Takubo ${ }^{1)}$, \\ Toshiki Takamizawa ${ }^{1,2)}$, Susumu Ando ${ }^{1,2)}$ and Masashi Miyazaki ${ }^{1,2)}$ \\ ${ }^{1)}$ Department of Operative Dentistry, Nihon University School of Dentistry, Tokyo, Japan \\ ${ }^{2)}$ Division of Biomaterials Science, Dental Research Center, Nihon University School of Dentistry, \\ Tokyo, Japan
}

(Received 21 April and accepted 22 May 2009)

\begin{abstract}
The purpose of this study was to investigate the development of shear bond strength of resin composites using self-etching primer systems. Four different types of self-etching primer systems with different combinations of their recommended resin composites were used. Bovine incisors were mounted in self-curing resin and the facial surfaces were wet ground on \#600-SiC paper to expose the dentin. The shear bond strengths of ten samples per test group were measured at a crosshead speed of $1.0 \mathrm{~mm} / \mathrm{min}$ after storage for 5,10 , and $60 \mathrm{~min}$, and $24 \mathrm{~h}$ in distilled water at $37^{\circ} \mathrm{C}$. One-way ANOVA followed by Dunnett's test $(\alpha=0.05)$ was used to examine the significance of differences between the mean bond strength at $24 \mathrm{~h}$ and each of the other storage periods. The dentin bond strengths of all the materials tested increased with prolonged storage time. Such differences in the changes in bond strength might have clinical implications if a restoration is subjected to high stress immediately after it has been placed. It is important to consider the development of dentin bond strength to allow the materials sufficient maturation time prior to functional loading or application of other forms of external stress. (J Oral Sci 51, 431-436, 2009)
\end{abstract}

\footnotetext{
Correspondence to Dr. Masashi Miyazaki, Department of Operative Dentistry, Nihon University School of Dentistry, 18-13 Kanda-Surugadai, Chiyoda-Ku, Tokyo 101-8310, Japan Tel: +81-3-3219-8141

Fax: +81-3-3219-8347

E-mail: miyazaki-m@dent.nihon-u.ac.jp
}

Keywords: self-etching primer; dentin; bond strength; progress in polymerization.

\section{Introduction}

The demand for esthetic dental materials has prompted the development of many bonding systems to provide sufficiently strong bonding to tooth structures. The clinical success of such adhesive systems depends on techniquesensitive factors such as blowing air on the primed tooth surface (1-3), the thickness of the applied bonding agent (4-6), and the light intensity of the curing unit $(7,8)$. To reduce variations in the degree of bonding induced by such technique-sensitive factors, the steps required for bonding procedures have been reduced (9). Self-etching primer systems have been developed to simplify and shorten bonding procedures (10). A self-etching primer forms a continuous layer between the composite resin and the tooth surface that has been simultaneously demineralized with acidic monomers, followed by penetration of the bonding agent into the tooth substrate (11-13).

In a clinical situation, debonding might occur soon after the restoration has been placed if it is subjected to stress. Such stress may be due to the restorative procedure, contraction shrinkage of the resin composite, or normal oral function such as mastication. Sufficient bond strength is one of the factors contributing to the clinical success of dental restorations, and has been measured by 24 -h data monitoring (14-16). Previous reports have highlighted the importance of early acquisition of adhesive bond strength, 
and shown that materials exposed to the oral environment must be strong enough to withstand both long-term and short-term forces (17). Although complete polymerization is not an indispensable requirement for clinical use, it must reach a minimum value that will enable the adhesives used to resist bonding failure when countering and finishing $(18,19)$. From a clinical standpoint, it is important to test the bonding characteristics of different types of adhesives within the early period after bonding.

The purpose of this study was to evaluate the development of shear bond strength at 5-60 min compared with that at $24 \mathrm{~h}$ after curing, and to investigate differences in behavior among the adhesive systems studied.

\section{Materials and Methods}

Four commercial bonding systems employing selfetching primers, Clearfil Mega Bond (Kuraray Medical Inc., Tokyo, Japan), FL-Bond (Shofu Inc., Kyoto, Japan), Mac Bond II (Tokuyama Dental Corp., Tokyo, Japan), and Unifil Bond (GC Corp., Tokyo, Japan) were used, as shown in Table 1. The adhesive systems were used in combination with the manufacturers' suggested resin composites. An Optilux 501 curing unit (sds Kerr, Orange, CA, USA), with a light intensity above $600 \mathrm{~mW} / \mathrm{cm}^{2}$ as measured with a dental radiometer (Model 100, Demetron/ Kerr), was used.

Mandibular incisors extracted from 2-3-year-old cattle were used as a substitute for human teeth (20-22). After removing the roots using a slow-speed saw with a diamondimpregnated disk (Isomet, Buehler Ltd., Lake Bluff, IL, USA), the pulps were removed, and the pulp chamber of each tooth was filled with cotton to avoid penetration of the embedding media. The labial surfaces of the bovine incisors were ground on wet 240 -grit $\mathrm{SiC}$ paper to a flat dentin surface. Each tooth was then mounted in self-curing acrylic resin (Tray Resin II, Shofu Inc., Kyoto, Japan) to expose the flattened area, and placed in tap water to reduce the increase in temperature resulting from the exothermic polymerization reaction of the acrylic resin. The final finish was accomplished by grinding on wet 600 -grit $\mathrm{SiC}$ paper. After ultrasonic cleaning with distilled water for 1 min to remove the excess debris, these surfaces were washed and dried with oil-free compressed air.

A piece of double-coated adhesive tape, bearing a 4-mmdiameter hole, was firmly attached to define the area for bonding. The adhesives were applied on the dentin surface for the time recommended by the manufacturers. A mold, $2.0 \mathrm{~mm}$ high and $4.0 \mathrm{~mm}$ in diameter, was used to form and hold the materials to the tooth surface. The mold was compactly filled with each resin composite, which was then light-activated for $30 \mathrm{~s}$.

After exposure of the resin composite to light, the finished specimens were transferred to distilled water at $37^{\circ} \mathrm{C}$ and stored for 5,10 , or $60 \mathrm{~min}$, or $24 \mathrm{~h}$. After removal of the molds, ten samples per group were tested in shear mode with a universal testing machine (Type 5500R,

Table 1 Materials tested in this study

\begin{tabular}{|c|c|c|c|c|}
\hline Bonding system & $\begin{array}{l}\text { Self-etching primer (Lot No.) } \\
\text { Main component }\end{array}$ & $\begin{array}{l}\text { Bonding agent (Lot No.) } \\
\text { Main component }\end{array}$ & $\begin{array}{l}\text { Resin composite } \\
\text { (Lot No.) }\end{array}$ & Manufacturer \\
\hline Mac-Bond II & $\begin{array}{l}\text { Primer (A: 042, B: 025B) } \\
\text { MAC-10, HEMA, acetone, } \\
\text { isopropyl alcohol, ethanol, } \\
\text { phosphate monomer } \\
\text { water }\end{array}$ & $\begin{array}{l}\text { Bonding Agent (0181) } \\
\text { MAC-10, HEMA, CQ, } \\
\text { bis-GMA, TEGDMA }\end{array}$ & $\begin{array}{l}\text { Estelite } \Sigma \text { Quick } \\
\text { (J021) }\end{array}$ & Tokuyama Dental Corp. \\
\hline UniFil Bond & $\begin{array}{l}\text { Self-etching primer (0807251) } \\
\text { 4-MET, HEMA, water, } \\
\text { ethanol }\end{array}$ & $\begin{array}{l}\text { Bonding Agent (008301) } \\
\text { TEGDMA, HEMA, } \\
\text { UDMA, CQ }\end{array}$ & $\begin{array}{l}\text { Solare } \\
(0711222)\end{array}$ & GC Corp. \\
\hline
\end{tabular}

MDP: 10-methacryloxydecyl di-hydrogen phosphate, HEMA: 2-hydroxyethyl methacrylate, PI: photo initiator, bis-GMA: 2, 2bis[4-(2-hydroxy-3-methacryloyloxypropoxy)]phenyl, 4-AET: 4-acryloyloxyethyl trimellitic acid, 4-AETA: 4-acryloyloxyethyl trimellitate anhydride, $\mathrm{CQ}$ : $d$-camphorquinone, MAC-10: 11 -methacryloxy-1,1-undecandicarboxylic acid, 4-MET: 4-methacryloyloxyethyl trimellitate, TEGDMA: triethylene glycol di-methacrylate, UDMA: urethane dimethacrylate. 
Instron Corp., Canton, MA, USA) at a crosshead speed of $1.0 \mathrm{~mm} / \mathrm{min}$. Shear bond strength values (MPa) were calculated from the peak load at failure divided by the specimen surface area. All the tests were conducted at a temperature of $23 \pm 1{ }^{\circ} \mathrm{C}$ and relative humidity $50 \pm 5 \%$.

The mean and standard deviation for each group were tested for homogeneity of variance using Bartlett's test, and then subjected to one-way ANOVA followed by Dunnett's test for significant differences between the mean bond strength at $24 \mathrm{~h}$ and each of the other storage periods. All statistical tests were performed at $P<0.05$ using the Sigma Stat software package (Ver. 3.1, SPSS Inc., Chicago, IL, USA).

After testing, the specimens were examined using an optical microscope (SZH-131, Olympus Ltd., Tokyo, Japan) at a magnification of $\times 10$ to determine the location of the bond failure. The test area on the tooth was divided into eight segments, and the percentage that was free of adhesive or restorative material was estimated. The types of failure were determined based on the predominant percentage of substrate-free material as: adhesive failure, cohesive failure in resin, or cohesive failure in dentin.

The fractured dentin surfaces were observed by scanning electron microscopy (SEM). All the SEM specimens were dehydrated in ascending concentrations of tert-butanol (50\% for $20 \mathrm{~min}, 75 \%$ for $20 \mathrm{~min}, 95 \%$ for $20 \mathrm{~min}$, and $100 \%$ for $2 \mathrm{~h}$ ), and then transferred to a critical-point dryer. The surfaces were coated in a vacuum evaporator (Quick Coater, Type SC-701, Sanyu Denshi Inc., Tokyo, Japan) with a thin film of gold. The specimens were then observed using field emission SEM (ERA-8800FE, Elionix Ltd., Tokyo, Japan).

\section{Results}

The data for mean shear bond strength at various time intervals are shown in Table 2. At $24 \mathrm{~h}$, all the materials tested exhibited the highest bond strength and the values obtained were $22.6 \pm 3.9 \mathrm{MPa}$ for Mega Bond, 21.6 \pm 2.3 $\mathrm{MPa}$ for FL-Bond, 21.3 $\pm 3.6 \mathrm{MPa}$ for Mac Bond áU, and $22.8 \pm 4.1 \mathrm{MPa}$ for UniFil Bond. The dentin bond strength of all materials tested increased with time, and this increasing tendency differed among the adhesive systems. The time when no significant difference in bond strength was observed compared with the value obtained at $24 \mathrm{~h}$ was $10 \mathrm{~min}$ for Mega Bond and Mac Bond áU, and $60 \mathrm{~min}$ for FL-Bond and UniFil Bond. The fracture pattern distributions after the bond strength test indicated that bond failure during the early storage period occurred more frequently at the dentin-adhesive interface. With prolonged storage, the incidence of cohesive failure of dentin and/or resin increased (Fig. 1; A-C).

\section{Discussion}

Although the ideal material for this type of study is human teeth, bovine teeth were used here as a substitute. One reason for this was that large numbers of teeth are required for bond strength tests, and it is difficult to obtain intact, extracted human teeth for laboratory studies. In addition, a standardized surface is needed to eliminate variations that might affect bond strength results, but human dentin surfaces show changes caused by exposure to saturated calcium phosphate in the saliva in the oral environment. Bovine teeth are easily obtainable and are reported to be a reliable substitute for human teeth in bonding studies (20-22). Care must therefore be taken when drawing conclusions about clinical relevance based on the results of this in vitro study, which was carried out under standard laboratory conditions $(23,24)$.

While laboratory testing of filling materials is not a substitute for clinical evaluation, testing of the bond

Table 2 Shear bond strengths (MPa) measured at various storage times

\begin{tabular}{lllll}
\hline Code & \multicolumn{1}{c}{$5 \mathrm{~min}$} & $10 \mathrm{~min}$ & $60 \mathrm{~min}$ & $24 \mathrm{~h}$ \\
\hline $\begin{array}{l}\text { Clearfil Mega Bond } \\
\text { FM }\end{array}$ & $\begin{array}{l}18.3(2.9) \\
{[4 / 5 / 1]}\end{array}$ & $\begin{array}{l}19.6(2.8)^{*} \\
{[2 / 6 / 2]}\end{array}$ & $\begin{array}{l}20.6(3.7)^{*} \\
{[2 / 8 / 0]}\end{array}$ & $\begin{array}{l}22.6(3.9)^{*} \\
{[1 / 9 / 0]}\end{array}$ \\
FL-Bond II & $17.3(2.3)$ & $17.5(2.6)$ & $19.6(3.4)^{*}$ & $21.6(2.3)^{*}$ \\
FM & {$[5 / 5 / 0]$} & {$[3 / 6 / 1]$} & {$[3 / 7 / 0]$} & {$[3 / 7 / 0]$} \\
Mac-Bond II & $17.8(1.9)$ & $19.1(2.3)^{*}$ & $21.1(2.1)^{*}$ & $21.3(3.6)^{*}$ \\
FM & {$[3 / 6 / 1]$} & {$[1 / 6 / 3]$} & {$[3 / 6 / 1]$} & {$[2 / 8 / 0]$} \\
UniFil Bond & $17.1(2.3)$ & $18.9(2.6)$ & $22.7(2.0)^{*}$ & $22.8(4.1)^{*}$ \\
FM & {$[4 / 6 / 0]$} & {$[2 / 6 / 2]$} & {$[1 / 8 / 2]$} & {$[0 / 9 / 1]$} \\
\hline
\end{tabular}

Values in parenthesis indicate standard deviations $(n=10)$.

Values with an asterisk indicate the time when there was no significant increase in bond strength compared with that at $24 \mathrm{~h}$ according to the Dunnet test $(P>0.05)$.

FM: fracture mode [adhesive failure/ cohesive failure in dentin/ cohesive failure in resin]. 
strength of adhesives to dentin can provide useful data on the effectiveness of bonding achieved by restorative systems. Many of the parameters that influence the strength of bonding to dentin have been cited, and classified into a broad range of groups, including substrate variables, etching variables, priming variables, storage variables, and testing variables (25). Shear bond testing is thought to be the most widely used type of bond strength testing for resin composites to dentin (26). However, this mode of bond strength test has been criticized because bond strength measurements are highly dependent on the geometry of the test arrangement, the nature of the load application, the presence or absence of an adhesive flash, and the materials involved. It has been reported that non-

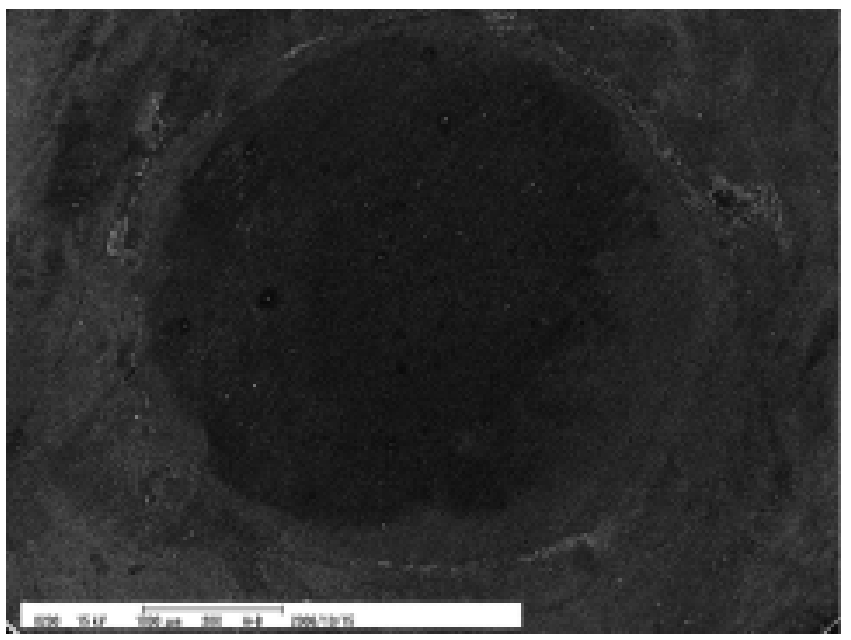

Fig. 1A

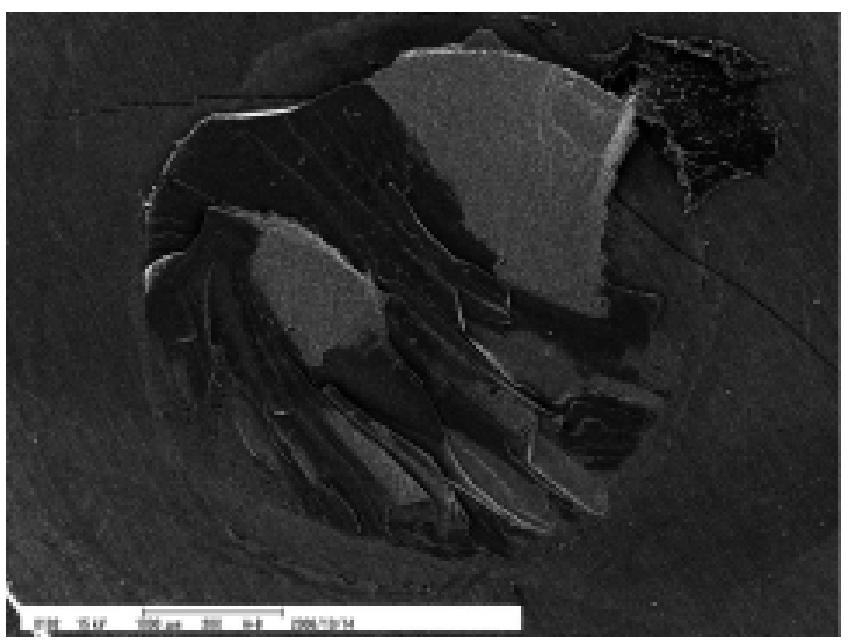

Fig. 1B uniform stresses act upon the bonded interface, thus bringing into question the concept of "average stress" for measurements of bond strength (27). The greatest emphasis on bond strength measurement has been placed on tensile bond strength (at right angles to the tooth/adhesive interface). Since all forces acting on an adhesive bond in vivo can be resolved into components acting at right angles to, and parallel with the interface (shear), measurement of shear strength is desirable for adequate evaluation of a bond (28).

A previous study that compared the chemical bonding efficacy of the functional monomers, MDP, 4-MET, and phenyl-P, reported that MDP had a high potential for chemical bonding to hydroxyapatite over a clinically feasible application period (29). Furthermore, the calcium salt of MDP was highly insoluble, and consequently was unable to withstand ultrasonic cleaning. According to the adhesion-decalcification concept (30), the less soluble the calcium salt of an acidic molecule, the more intense and stable the molecular adhesion to a hydroxyapatite-based substrate. The superior bonding performance of MDP might have been reflected in the actual adhesive potential to dentin. Accordingly, an increase in bond strength was observed for the Clearfil Mega Bond system within a short period of time after light-curing.

The results of this study indicated that the bond strengths of self-etching primer systems increased with time, and that this could be explained by progressive polymerization of the material. The changes in mechanical properties with time might reflect the extent of the continuing

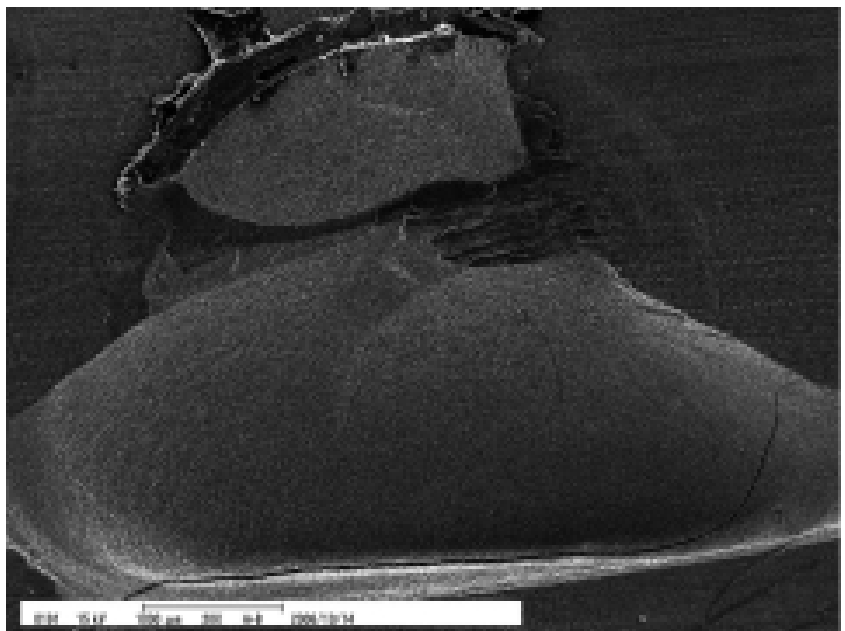

Fig. 1C

Fig. 1 Representative SEM observations of the fractured surface of Clearfil Mega Bond after shear bond strength testing. Bonding failure between the dentin and the adhesive is apparent (A) for a specimen in the 5-min group. Cohesive failures at the adhesive resin (B) and dentin (C) sides were observed with longer specimen storage durations. 
polymerization reaction. The shear bond strength may be at least partly related to the modulus of the adhesive. An increase in the modulus of elasticity will result in a more even distribution of stress over the bonded area, and less concentration at the point of load application. In extreme cases where the modulus value is low, the fracture will be due to "peeling" rather than shearing. The mechanical bond strength of adhesives increases roughly in the order of ascending shear bond strength.

As it is imperative for any restoration to support initial masticatory loading and to tolerate thermal fatigue, it is important to assess bond strength immediately after the restoration procedure. In clinical situations, the most valuable bond strength measurements are those taken at less than $10 \mathrm{~min}$ after placement, and bond strength testing should ideally be performed as soon as possible after this. Conversely, the increases in bond strength were observed under conditions that did not reflect the clinical situation, as any bonded interface is subjected to stresses after placement. Thus the main limitation of this study was that the development of bond strength of self-etching primer systems was assessed under laboratory conditions.

\section{Acknowledgments}

This work was supported, in part, by a Grant-in-Aid for Scientific Research (C) 20592237 from the Japan Society for the Promotion of Science, the Sato Fund, and a grant from the Dental Research Center of Nihon University School of Dentistry, Japan.

\section{References}

1. Shinkai K, Suzuki S, Katoh Y (2006) Effect of airblowing variables on bond strength of all-in-one adhesives to bovine dentin. Dent Mater J 25, 664668.

2. Sadr A, Shimada Y, Tagami J (2007) Effects of solvent drying time on micro-shear bond strength and mechanical properties of two self-etching adhesive systems. Dent Mater 23, 1114-1119.

3. Garcia FCP, Almeida JCF, Osorio R, Carvalho RM, Toledano M (2009) Influence of drying time and temperature on bond strength of contemporary adhesives to dentine. J Dent 37, 315-320.

4. Zheng L, Pereira PN, Nakajima M, Sano H, Tagami J (2001) Relationship between adhesive thickness and microtensile bond strength. Oper Dent 26, 97 104.

5. Nakaoki Y, Sasakawa W, Horiuchi S, Nagano F, Ikeda T, Tanaka T, Inoue S, Uno S, Sano H, Sidhu SK (2005) Effect of double-application of all-in-one adhesives on dentin bonding. J Dent 33, 765-772.
6. Lodovici E, Reis A, Geraldeli S, Ferracane JL, Ballester RY, Rodrigues Filho LE (2009) Does adhesive thickness affect resin-dentin bond strength after thermal/load cycling? Oper Dent 34, 58-64.

7. Yamamoto A, Tsubota K, Takamizawa T, Kurokawa H, Rikuta A, Ando S, Takigawa T, Kuroda T, Miyazaki M (2006) Influence of light intensity on dentin bond strength of self-etch systems. J Oral Sci 48, 21-26.

8. Shinkai K, Suzuki S, Katoh Y (2008) Effect of light intensity for adhesives on shear bond strength to dentin. Dent Mater J 27, 660-665.

9. Van Meerbeek B, De Munck J, Yoshida Y, Inoue S, Vargas M, Vijay P, Van Landuyt K, Lambrechts P, Vanherle G (2003) Buonocore memorial lecture. Adhesion to enamel and dentin: current status and future challenges. Oper Dent 28, 215-235.

10. Van Meerbeek B, Van Landuyt K, De Munck J, Hashimoto M, Peumans M, Lambrechts P, Yoshida Y, Inoue S, Suzuki K (2005) Technique-sensitivity of contemporary adhesives. Dent Mater J 24, 1-13.

11. Miyazaki M, Onose H, Moore BK (2002) Analysis of the dentin-resin interface by use of laser Raman spectroscopy. Dent Mater 18, 576-580.

12. Wang Y, Spencer P (2002) Quantifying adhesive penetration in adhesive/dentin interface using confocal Raman microspectroscopy. J Biomed Mater Res 59, 46-55.

13. Wang Y, Spencer P (2004) Physiochemical interactions at the interfaces between self-etch adhesive systems and dentine. J Dent 32, 567-579.

14. Watanabe I, Nakabayashi N (1994) Measurement methods for adhesion to dentine: the current status in Japan. J Dent 22, 67-72.

15. Miyazaki M, Oshida Y, Xirouchaki L (1996) Dentin bonding system. Part I: literature review. Biomed Mater Eng 6, 15-31.

16. Burke FJT, Hussain A, Nolan L, Fleming GJP (2008) Methods used in dentine bonding tests: an analysis of 102 investigations on bond strength. Eur J Prosthodont Restor Dent 16, 158-165.

17. Burrow MF, Nikaido T, Satoh M, Tagami J (1996) Early bonding of resin cements to dentin - effect of bonding environment. Oper Dent 21, 196-202.

18. Sadek FT, Goracci C, Cardoso PEC, Tay FR, Ferrari M (2005) Microtensile bond strength of current dentin adhesives measured immediately and 24 hours after application. J Adhes Dent 7, 297-302.

19. Sadek FT, Calheiros FC, Cardoso PE, Kawano Y, Tay F, Ferrari M (2008) Early and 24-hour bond strength and degree of conversion of etch-and-rinse 
and self-etch adhesives. Am J Dent 21, 30-34.

20. Nakamichi I, Iwaku M, Fusayama T (1983) Bovine teeth as possible substitutes in the adhesion test. J Dent Res 62, 1076-1081.

21. Fowler CS, Swartz ML, Moore BK, Rhodes BF (1992) Influence of selected variables on adhesion testing. Dent Mater 8, 265-269.

22. Schilke R, Bauss O, Lisson JA, Schuckar M, Geurtsen W (1999) Bovine dentin as a substitute for human dentin in shear bond strength measurements. Am J Dent 12, 92-96.

23. Fonseca RB, Haiter-Neto F, Carlo HL, Soares CJ, Sinhoreti MA, Puppin-Rontani RM, Correr-Sobrinho L (2008) Radiodensity and hardness of enamel and dentin of human and bovine teeth, varying bovine teeth age. Arch Oral Biol 53, 1023-1029.

24. Wegehaupt F, Gries D, Wiegand A, Attin T (2008) Is bovine dentine an appropriate substitute for human dentine in erosion/abrasion tests? J Oral Rehabil 35, 390-394.

25. Pashley DH, Sano H, Ciucchi B, Yoshiyama M,
Carvalho RM (1995) Adhesion testing of dentin bonding agents: a review. Dent Mater 11, 117-125.

26. al-Salehi SK, Burke FJ (1997) Methods used in dentin bonding tests: an analysis of 50 investigations on bond strength. Quintessence Int 28, 717-723.

27. Van Noort R, Noroozi S, Howard IC, Cardew G (1989) A critique of bond strength measurements. J Dent 17, 61-67.

28. DeHoff PH, Anusavice KJ, Wang Z (1995) Threedimensional finite element analysis of the shear bond test. Dent Mater 11, 126-131.

29. Yoshida Y, Nagakane K, Fukuda R, Nakayama Y, Okazaki M, Shintani H, Inoue S, Tagawa Y, Suzuki K, De Munck J, Van Meerbeek B (2004) Comparative study on adhesive performance of functional monomers. J Dent Res 83, 454-458.

30. Yoshioka M, Yoshida Y, Inoue S, Lambrechts P, Vanherle G, Nomura Y, Okazaki M, Shintani H, Van Meerbeek B (2002) Adhesion/decalcification mechanisms of acid interactions with human hard tissues. J Biomed Mater Res 59, 56-62. 